\title{
Balık Çiftliği Atık Çamuru Uygulanan Turunç Çöğürlerinde Yaprak Besin Element Düzeylerinin Belirlenmesi
}

\section{Murat GÜNERi}

\author{
${ }^{\prime}$ Muğla Sıtkı Koçman Üniversitesi Ortaca Meslek Yüksek Okulu, Muğla.
}

Öz: Çalıșmanın amacı, alabalık üretim havuzlarında ortaya çıkan sedimantasyon ürünü atık çamurunun turunç (Citrus aurantium L.) çöğürü yetiștiriciliğinde bitki besin elementleri içeriğine etkisini ve bitki beslemede, mineral gübre yerine ikame edilebilirliğini belirlemektir. Alabalık yetiștirme çiftliği havuzundan toplanan atık çamur, önce gölgede kurutulmuș, daha sonra $0,5,10$ ve $20 \mathrm{~g} \mathrm{~kg}^{-1}$ dozlarında, turunç bitkilerinin bulunduğu saksı harç ortamına karıștırılmıștır. Aynı zamanda, her farklı atık dozu için; 0, \%50 ve \% 100 doz olmak üzere 3 farklı Hoagland besin solüsyonu uygulanmıștır.

Yapraklarda N, P, K, Ca, Mg, Na, Fe, Zn, Mn ve Cu besin elementleri belirlenmiștir. Uygulanan atık dozları kontrole göre, N, $\mathrm{Zn}$ ve $\mathrm{Cu}$ kapsamını genel olarak önemli düzeyde artıırmıștır. Hoagland solüsyonunun farklı doz uygulamalarında ise; $\mathrm{N}, \mathrm{K}$ ve $\mathrm{Zn}$ kapsamları kontrole göre artmıș, fakat $\mathrm{Fe}$ ve $\mathrm{Na}$ azalmıștır. Atık dozu ile Hoagland dozlarının birlikte kullanıldığı kombinasyonlarda N: \%।.40 - 4.64; P: \%0.22 - 0.34, K: \%0.47 - 2.6।, Ca: \%2.35 - 3.07, Mg: \%0.28 - 0.34, Na: I58 - $664 \mathrm{mg}$ $\mathrm{kg}^{-1}$, Fe: 73.3 - $126.7 \mathrm{mg} \mathrm{kg}^{-1}$, Zn: $23.3-46.3 \mathrm{mg} \mathrm{kg-1}$, Mn: 9.3 - $30.7 \mathrm{mg} \mathrm{kg}^{-1}$ ve Cu: 2.0 - $19.7 \mathrm{mg} \mathrm{kg}^{-1}$ aralığında belirlenmiștir.

Sonuç olarak balık atığı, turunç bitkilerinde beslenmeyi olumlu yönde etkilemiş, aynı zamanda Hoagland solüsyonu ile genellikle benzer sonuçlar vermiștir. Bu nedenle bașta organik tarım olmak üzere bitki yetiștiriciliğinde, tek bașına veya mineral gübreler ile karıșım halinde, gübre kaynağı olarak kullanılabileceği değerlendirilmektedir.

Anahtar Kelimeler: balık atı̆̆ı, Citrus aurantium L.

\section{Determination of Nutrient Element Contents in Sour Orange Seedling Leaves after the Application with Fish Farm Sludge}

Abstract: The aim of the study is to determine the effect of trout pool sedimentation wastes treatments on leaf nutrient contents in sour orange seedlings and subtitution chance in comparison to mineral fertilizers in plant nutrition.

The waste sludge collected from the farming pond was firstly air dried and 0, 5, 10 and $20 \mathrm{~g} \mathrm{~kg}^{-1}$ doses of waste material applied to sour orange seedling pots. At the same time, for each different solid waste doses, three different hoagland nutrient solutions were applied as $0,50 \%$ and $100 \%$ doses.

$\mathrm{N}, \mathrm{P}, \mathrm{K}, \mathrm{Ca}, \mathrm{Mg}, \mathrm{Na}, \mathrm{Fe}, \mathrm{Zn}, \mathrm{Mn}$ and $\mathrm{Cu}$ contents were determined as leaf nutrients in the study. According to the results, waste applications increased significantly $\mathrm{N}, \mathrm{Zn}$ and $\mathrm{Cu}$ contents of leaf in comparison to the control. In different dose applications of Hoagland solution resulted as increase in $\mathrm{N}$, $\mathrm{K}$ and $\mathrm{Zn}$ contents but decreased $\mathrm{Fe}$ and $\mathrm{Na}$ contents in comparison to the control. Application of waste and Hoagland combination doses

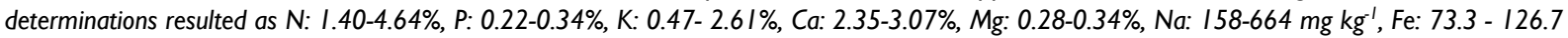
$\mathrm{mg} \mathrm{kg} \mathrm{g}^{-1}, \mathrm{Zn:} 23.3-46.3 \mathrm{mg} \mathrm{kg}^{-1}, \mathrm{Mn}: 9.3-30.7 \mathrm{mg} \mathrm{kg}^{-1}$ and $\mathrm{Cu}: 2.0-19.7 \mathrm{mg} \mathrm{kg}^{-1}$.

As a result, fish sludge effect nutrients positively in sour orange seedling plants. Generally, the waste and Hoagland solution gave similar results. For this reason, it is evaluated that it can be used as a fertilizer source either alone, especially in organic farming, or in combination with mineral fertilizers in conventional farming.

Keywords: fish waste, Citrus aurantium L.

\section{GiRiș}

Farklı kaynaklardan ortaya çıkan atıkların bertaraf edilmesi ve değișik alanlarda geri dönüșümünün sağlanması, sürdürülebilir bir kalkınma ve yașam kalitesinin korunması açısından bir zorunluluktur. Atıkların, tarımsal faaliyetlerde kullanılmasına yönelik çalıșmalar bu nedenle önem kazanmıștır.

Günümüzde organik kökenli atıkların, bitkisel üretimde kullanımı ile olumlu sonuç elde edildiğini bildiren çok sayıda çalıșma yer almaktadır (Akat ve ark., 2013; Arienzo ve ark., 2009; Așık ve ark., 2010; Brod ve ark., 2012; Celis ve ark., 2008; Delibacak ve Ongun, 2016; Pereira ve ark., 20II; Smith, 1985; Tuna ve ark., 2012; Uzun ve Bilgili, 201I). Bu kapsamda, akuakültür atıklarının iyi bir besin kaynağı olabileceği ve bitki yetiștiriciliğinde bașarılı bir șekilde kullanılabileceği belirtilmektedir (Adler ve ark., 2003; Celis ve Sandoval 2010; Illera-Vives ve ark., 2015a; Moccia ve ark., 2007; Nair ve ark., 2006; Palada ve ark., 1999; Rakocy ve ark., 2004).

Balık üretim çiftliklerinde, havuzlarda her yıl çok miktarda sedimantasyon atı̆̆ birikmekte, bu atıklar su kaynaklarına deșarj edilmesi durumunda çevreyi kirletmektedir (Wang ve ark., 2012). Oysa yapilan çalıșmalarda bu atıkların besin elementleri yönünden oldukça zengin olduğu belirtilmektedir. Çökelmiș balık fekal atığının kimyasal bileșimi incelenmiștir. Buna göre,

Sorumlu Yazar: gmurat@mu.edu.tr

Geliș Tarihi: 18 Ağustos 2017

Kabul Tarihi: 30 Mayıs 2018 
I2 alabalık çiftliğinden alınan taze gübre örneklerinde, kuru ağırlıkta ortalama \%2.83 N, \%2.54 P, \%0.10 K, \%6.99 Ca ve \%0.53 Mg bulunduğu tespit edilmiștir. Sığır, kümes hayvanları ve domuz gübresi ile karșılaștırıldığında; $\mathrm{N}, \mathrm{P}, \mathrm{Ca}$, ve $\mathrm{Mg}$ benzer, $\mathrm{K}$ ise düșük seviyede bulunmuștur. Balık gübresinin $\mathrm{Mn}, \mathrm{Cd}, \mathrm{Cr}, \mathrm{Pb}, \mathrm{Fe}$, ve $\mathrm{Zn}$ içeriği bakımından diğer hayvansal gübrelere göre daha yüksek; As, Se, Co, Ni bakımından ise daha düșük değerlere sahip olduğu, sonuç olarak taze balık gübresinin diğer çiftlik hayvanları gübreleri ile kimyasal içerik yönünden benzer olduğu görülmüștür (Naylor ve ark., 1999). Muğla'da alabalık üretim tesisinden elde edilen atığın fiziksel ve kimyasal analizlerine göre; $\mathrm{pH}$ 7.08, EC I.8I3 mS cm-1 toplam N \%I.37, P \%0.32, K $\% 0.53$, Ca \% 0.38, Mg \%6.33, Na \%0.I2, Fe \%І.II, Cu 27.21 ppm, Zn 309.88 ppm, Mn 338.38 ppm, Ni 39.70 Ppm, Co 18.10 ppm, Cd 2.63 ppm, Cr 13.75 ppm ve $\mathrm{Pb}$ 6.86 ppm olarak belirlenmiștir (Demirkan ve ark. 2017). Balık atıkları mineral, protein, karbonhidrat içerir ve toprak ile karıșımlarında besin maddesi kazandırır (Rebecca ve ark., 20l4).

Balık havuzlarındaki su ve içinde erimiș halde bulunan besin maddelerinin bitki yetiștiriciliğinde kullanılmasını kapsayan Aquaponik kültür yapılabilmektedir. Böylece balıkların atıkları bitkiler için besin maddesi olarak kullanılabilmektedir (Demir ve Çakırer, 20I4). Deniz yosunu ve balık atığının yüksek organik madde ve besin maddesi ile gübre elde etmek için birlikte kompostlanabileceği, bununla birlikte, çoğunlukla organik formda olan bu besinleri bitkilere hazır hale getirmek için mineralleștirilmesinin gerekli olduğu belirtilmektedir (Illera-Vives ve ark., 20I5b). Balık çiftliği atık suyu kullanılarak yağmurlama ve damla sulama sistemleri ile patates bitkilerinde sulama yapılmıs, yağmurlama sulama sistemi ile mineral gübre kullanımında en az $\% 40$, sulama suyunda en az \%100 tasarruf sağlamıștır (Eid ve ark., 2014).

Çizelge I. Denemede kullanılan modifiye edilmiș Hoagland çözeltisi

\begin{tabular}{|c|c|c|}
\hline Element & Miktar $\left(\mathrm{mgkg}^{-1}\right)$ & Kimyasal Kaynaklar \\
\hline $\mathrm{N}$ & 210.00 & $\mathrm{NH}_{4} \mathrm{NO}_{3}(\% 33 \mathrm{~N})$ \\
\hline$P$ & 30.00 & $\mathrm{NH}_{4} \mathrm{H}_{2} \mathrm{PO}_{4}(\% 12 \mathrm{~N}+\% 6 \mathrm{I} 2 \mathrm{O} 5)$ \\
\hline K & 240.00 & $\mathrm{~K}_{2} \mathrm{SO}_{4}\left(\% 5 \mathrm{I} \mathrm{K}{ }_{2} \mathrm{O}+\% 46 \mathrm{SO}_{3}\right)$ \\
\hline $\mathrm{Ca}$ & 200.00 & $\mathrm{Ca}\left(\mathrm{NO}_{3}\right)_{2} .4 \mathrm{H}_{2} \mathrm{O}(\% \mathrm{I} .5 \mathrm{~N}+\% 19 \mathrm{CaO})$ \\
\hline $\mathrm{Mg}$ & 50.00 & $\mathrm{MgSO}_{4} \cdot 7 \mathrm{H}_{2} \mathrm{O}(\% 10 \mathrm{MgO})$ \\
\hline $\mathrm{Fe}$ & 4.00 & $\mathrm{Na}_{2} \mathrm{Fe}-\mathrm{EDTA}(\% \mathrm{I} .5 \mathrm{Fe})$ \\
\hline $\mathrm{Zn}$ & 4.00 & $\mathrm{ZnSO}_{4} .7 \mathrm{H}_{2} \mathrm{O}$ \\
\hline $\mathrm{Mn}$ & 3.00 & $\mathrm{MnSO}_{4} \cdot \mathrm{H}_{2} \mathrm{O}$ \\
\hline B & 1.50 & $\mathrm{H}_{3} \mathrm{BO}_{3}$ \\
\hline $\mathrm{Cu}$ & 0.60 & $\mathrm{CuSO}_{4} .5 \mathrm{H}_{2} \mathrm{O}$ \\
\hline Mo & 0.05 & $\left(\mathrm{NH}_{4}\right) 6 \mathrm{Mo}_{0} \mathrm{O}_{24.4} 4 \mathrm{H}_{2} \mathrm{O}$ \\
\hline
\end{tabular}

Bu çalıșmada, balık üretim havuzlarında olușan sedimantasyon ürünü atık çamurunun turunç çöğürü yetiștiriciliğinde bitki besin elementleri içeriğine etkisi ve mineral gübre yerine ikame edilebilirliğini belirlemek amaçlanmıștır.

\section{MATERYAL ve YÖNTEM}

Çalıșma, Ortaca Meslek Yüksekokulu'nda, sera koșullarında saksı denemesi șeklinde gerçekleștirilmiștir. Bitki materyali olarak turunç (Citrus aurantium L.) çöğürleri kullanılmıștır. Turunç tohumları 2 kısım torf, I kısım perlit içeren harç ortamına ekilmiș, elde edilen çöğürler, $10 \mathrm{~cm}$ boyunda iken mart ayının ikinci yarısında, 10 litrelik saksı içine șașırtılmıștır.

Saksılarda, yetiștirme ortamı olarak 4 kısım torf, 2 kısım perlit ve I kısım kum kullanılmıș, içerisine herhangi bir besin elementi ilavesi yapılmamıștır.

Atık, Muğla ili Köyceğiz ilçesinde bulunan Gökkușağı Alabalık türü (Oncorhynchus mykiss) yetiștirme çiftliği havuzundan kürek ile toplanmıștır. Çamur daha sonra hava ile kurutulmuș ve topaklașan kısımları dövülerek homojen hale getirilmiștir. Kurutulmuș atık çamurundan $0,5,10$ ve $20 \mathrm{~g} \mathrm{~kg}^{-1}$ oranlarında olmak üzere 4 farklı doz yetiștirme ortamına karıștırılmak suretiyle uygulanmıștır. Kontrol grubunu $0 \mathrm{~g} \mathrm{~kg}^{-1}$ doz olușturmuștur.

Balık atığının besin solüsyonu yerine ne oranda ikame edilebileceğini belirleyebilmek için turunç çöğürleri șașırtıldıkları dönemden itibaren deneme sonuna kadar; $0, \% 50$ ve $\% 100$ doz olmak üzere 3 farklı konsantrasyona sahip Hoagland besin solüsyonu ile sulanmıștır (Çizelge I). Kontrol bitkilerine aynı miktarlarda sadece su uygulanmıștır.

Deneme 3 tekerrürlü ve her tekerrürde 3 bitki bulunan iki faktörlü tesadüf parselleri deneme desenine göre kurulmuștur. Çalıșmadaki tüm saksı sayısı 108 adettir.

Kasım ayında alınan 6-7 aylık yaprak örneklerinde; N, P, $\mathrm{K}, \mathrm{Ca}, \mathrm{Mg}, \mathrm{Na}, \mathrm{Fe}, \mathrm{Zn}, \mathrm{Mn}$ ve $\mathrm{Cu}$ besin element analizleri

10 
yapılmıștır. Yaprak örnekleri, besin element analizleri için $65^{\circ} \mathrm{C}$ ' de etüvde kurutulduktan sonra öğütülmüștür. Yaprakta toplam $\mathrm{N}$ modifiye Kjeldahl yöntemi ile saptanmıștır (Mills ve Jones, 1996). Yaș yakma yöntemi ile hazırlanan ekstraklarda $\mathrm{P}$ kolorimetrede; $\mathrm{K}, \mathrm{Na}$ ve $\mathrm{Ca}$ alev fotometresi ile; $\mathrm{Mg}, \mathrm{Fe}, \mathrm{Zn}, \mathrm{Mn}$ ve $\mathrm{Cu}$ ise Atomik Absorbsiyon Spektrofotometre'de okunarak belirlenmiștir (Kacar, 1972; Mills ve Jones, 1996).

Elde edilen veriler SAS istatistik paket programı kullanılarak (Anonim, 1989), ortalamalar arasında LSD testi ile karșılaștırma yapılmıștır.

\section{BULGULAR ve TARTIȘMA}

GÜNERI M

Turunç çöğürlerinin makro ve mikro besin elementi kapsamı üzerine farklı dozlarda balık atığı ve Hoagland uygulamalarının etkilerini belirleyebilmek için yaprak analizleri yapılmıștır.

Balık atığının yaprak N, P, K, Ca, Mg, Na, Fe, Zn, Mn ve Cu kapsamları üzerindeki etkileri Çizelge 2'de verilmiștir. Buna göre; yaprak N, Zn ve Cu kapsamlarında artıș yönünde istatistiksel olarak önemli farklılıklar olduğu belirlenmiștir.

Hoagland uygulamalarında ise uygulanan doz artıșına bağlı olarak yaprak N, P, K, Na, Fe ve Zn kapsamlarında artıș veya azalıș yönünde istatistiksel olarak önemli değișmeler tespit edilmiștir (Çizelge 3).

Çizelge 2. Turunç çöğürünün yaprak besin elementi kapsamı üzerine balık atığının etkisi

\begin{tabular}{|c|c|c|c|c|c|}
\hline & $\mathrm{N}$ & $P$ & $\mathrm{~K}$ & $\mathrm{Ca}$ & $\mathrm{Mg}$ \\
\hline Uygulamalar & \multicolumn{5}{|c|}{ (\%) } \\
\hline $\mathrm{Al}$ & $1.81 \mathrm{~b}$ & 0.27 & $\mathrm{I} .57$ & 2.60 & 0.32 \\
\hline $\mathrm{A} 2$ & $3.10 \mathrm{a}$ & 0.28 & 1.59 & 2.69 & 0.33 \\
\hline A3 & $2.96 \mathrm{a}$ & 0.29 & 1.48 & 2.74 & 0.32 \\
\hline A4 & $2.73 \mathrm{ab}$ & 0.30 & 1.50 & 2.73 & 0.31 \\
\hline LSD & $0.951 *$ & ö.d. & ö.d. & ö.d. & ö.d. \\
\hline \multirow[b]{2}{*}{ Uygulamalar } & $\mathrm{Na}$ & $\mathrm{Fe}$ & $\mathrm{Zn}$ & $M n$ & $\mathrm{Cu}$ \\
\hline & \multicolumn{5}{|c|}{$\left(\mathrm{mg} \mathrm{kg}^{-1}\right)$} \\
\hline $\mathrm{Al}$ & 420 & 93.3 & $32.0 \mathrm{~b}$ & 21.3 & $5.6 \mathrm{~b}$ \\
\hline $\mathrm{A} 2$ & 393 & 95.6 & $34.9 \mathrm{a}$ & 18.2 & $8.7 \mathrm{ab}$ \\
\hline A3 & 345 & 84.4 & $34.6 a b$ & 16.2 & $11.2 \mathrm{a}$ \\
\hline A4 & 262 & 101.1 & $36.6 \mathrm{a}$ & 19.3 & $5.0 \mathrm{~b}$ \\
\hline LSD & ö.d. & ö.d. & $2.79 *$ & ö.d. & $5.59 * *$ \\
\hline
\end{tabular}

ö.d. : önemli değil, * : \%5 seviyesinde önemli, **: \%। seviyesinde önemli. Aynı sütunda farklı harflerle gösterilen ortalamalar arasındaki farklılık istatistiki olarak önemlidir. A: Atık (Al:0 $\left.\mathrm{g} \mathrm{kg}^{-1}, \mathrm{~A} 2: 5 \mathrm{~g} \mathrm{~kg}^{-1}, \mathrm{~A} 3: 10 \mathrm{~g} \mathrm{~kg}^{-1}, \mathrm{~A}^{2}: 20 \mathrm{~g} \mathrm{~kg}^{-1}\right)$

Çizelge 3. Turunç çöğürünün yaprak besin elementi kapsamı üzerine Hoagland solüsyonunun etkisi

\begin{tabular}{|c|c|c|c|c|c|}
\hline & $\mathrm{N}$ & $\mathrm{P}$ & $\mathrm{K}$ & $\mathrm{Ca}$ & $\mathrm{Mg}$ \\
\hline Uygulamalar & \multicolumn{5}{|c|}{ (\%) } \\
\hline $\mathrm{HI}$ & $\mathrm{I} .63 \mathrm{~b}$ & $0.28 \mathrm{~b}$ & $0.55 \mathrm{c}$ & 2.58 & 0.33 \\
\hline $\mathrm{H} 2$ & $2.91 \mathrm{a}$ & $0.32 \mathrm{a}$ & $1.65 \mathrm{~b}$ & 2.58 & 0.31 \\
\hline $\mathrm{H} 3$ & $3.4 \mathrm{I} a$ & $0.26 \mathrm{~b}$ & $2.4 \mathrm{I} a$ & 2.90 & 0.33 \\
\hline LSD & $0.824^{* *}$ & $0.021 * *$ & $0.183^{* *}$ & ö.d. & ö.d. \\
\hline \multirow[b]{2}{*}{ Uygulamalar } & $\mathrm{Fe}$ & $\mathrm{Zn}$ & $M n$ & $\mathrm{Cu}$ & $\mathrm{Na}$ \\
\hline & \multicolumn{5}{|c|}{$\left(\mathrm{mg} \mathrm{kg}^{-1}\right)$} \\
\hline $\mathrm{HI}$ & $104.2 \mathrm{a}$ & $26.8 \mathrm{c}$ & 19.7 & 13.1 & $525 \mathrm{a}$ \\
\hline $\mathrm{H} 2$ & $90.0 \mathrm{~b}$ & $33.7 \mathrm{~b}$ & 15.8 & 2.6 & $234 b$ \\
\hline $\mathrm{H} 3$ & $86.7 b$ & $43.0 \mathrm{a}$ & 20.8 & 3.3 & $307 b$ \\
\hline LSD & $11.5^{*}$ & $2.42 * *$ & ö.d. & ö.d. & $109.9 * *$ \\
\hline
\end{tabular}

ö.d. : önemli değil, * : \%5 seviyesinde önemli, ** : \%। seviyesinde önemli. Aynı sütunda farklı harflerle gösterilen ortalamalar arasındaki farklılık istatistiki olarak önemlidir. $\mathrm{H}$ : Hoagland ( $\mathrm{HI}: 0, \mathrm{H} 2$ : \%50, H3: \% 00 doz)

Balık atığı ve Hoagland çözeltisinin birlikte uygulandığı farklı kombinasyonların yaprak makro ve mikro besin elementleri kapsamları üzerine etkisi Șekil I, 2, 3, 4, 5, 6, 7, 8, 9 ve 10'da verilmiștir. Besin elementlerinden sadece Fe (Lsd:23.0**) ve Mn (Lsd:10.66**) için uygulama kombinasyonları arasındaki fark istatistiksel olarak önemli bulunmuștur $(\mathrm{P}<0.0 \mathrm{I})$.

Yaprak besin elementleri kapsamları için elde edilen veriler kontrol ( $0 \mathrm{~g} \mathrm{~kg}^{-1}$ atık +0 doz Hoagland grubu) bitkilerine göre değerlendirildiğinde; uygulamalar ile, $\mathrm{N}$ kapsamı \%23। (5 g kg-1 atık + \% I00 doz Hoagland grubu), 
P \%26 (20 g kg-1 atık + \%50 doz Hoagland grubu), $\mathrm{K}$ $\% 290$ (5 g kg-1 atık + \% I00 doz Hoagland grubu), Ca \%3। (5 g kg-1 atık + \% 100 doz Hoagland grubu), Fe \%46 (20 g $\mathrm{kg}^{-1}$ atık + 0 doz Hoagland grubu), Zn \%99 (20 g kg-1 atık + \% 100 doz Hoagland grubu) ve Cu \% I 9 (I0 g kg-1 atık + 0 doz Hoagland grubu) oranında artıș göstermiștir. Bu yönüyle uygulamaların bitki beslemede olumlu etkisi olduğu belirtilebilir. Buna karșın Mn \%66 (20 g kg-1 atık + 0 doz Hoagland grubu) ve $\mathrm{Na} \% 76$ (20 g kg-1 atık + \%50 doz Hoagland grubu) oranında azalmıș, Mg kapsamında ise belirgin bir değișim meydana gelmemiștir.

Azot kapsamı \%l.40 (kontrol) - \%4.64 (5 g kg-1 atık + $\% 100$ doz Hoagland), $\mathrm{P}$ ise \%0.22 (0 g kg-1 atık+ \%।00 Hoagland) - \%0.34 (20 $\mathrm{g} \mathrm{kg}^{-1}$ atık + \%50 doz Hoagland) arasında değișim göstermiștir (Șekil I ve Șekil 2).

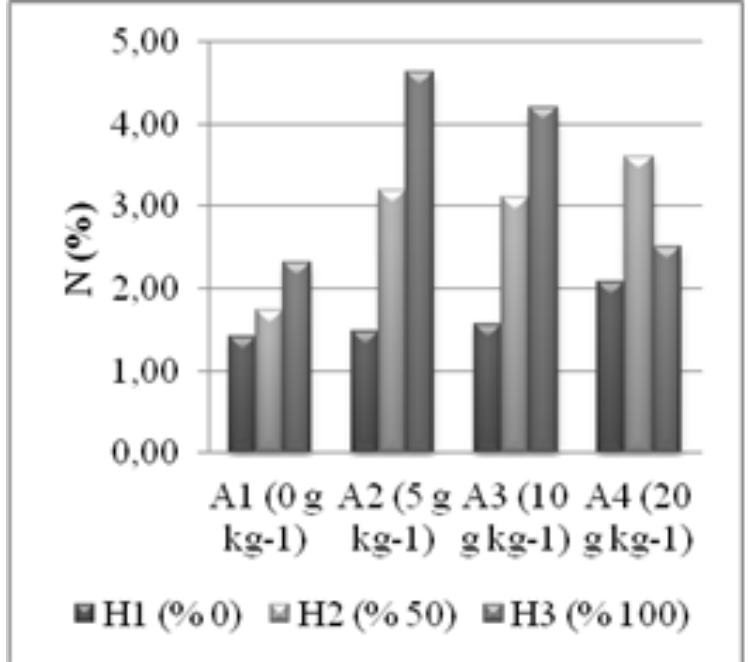

Șekil I. Atık ve Hoagland uygulamalarının N (\%) kapsamı üzerine etkisi (A: Atık $\mathrm{H}$ : Hoagland)

Uygulanan atık dozlarının, Hoagland dozlarına benzer șekilde $\mathrm{N}$ kapsamında artıș meydana getirmesi, atık materyalin turunç çöğürlerinde bitki beslemede $N$ ihtiyacının karșılanması için kullanılabileceğini göstermektedir.

Smith (1966), Koo ve ark. (1984) ve Jones ve ark. (199I)'nın önerdikleri $N$ referans değerleri (sırasıyla \%2.5, \%2.2 ve \%2.2) çalıșmamız ile uyumlu, P değerleri (sırasıyla \%0.12, \%0.09 ve \%0.12) ise çalıșmadan daha düșük bulunmuștur.

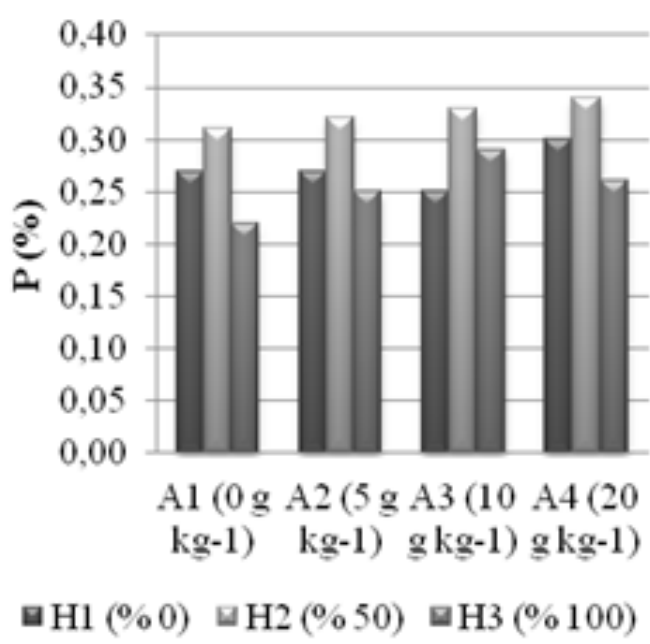

Șekil 2. Atık ve Hoagland uygulamalarının P (\%) kapsamı üzerine etkisi (A: Atık $\mathrm{H}$ : Hoagland)

Graber ve Junge (2009) artan dozlardaki akuakültür uygulamaları ile domates, patlıcan ve hıyar bitkilerinde $\mathrm{N}$ ve $P$ içeriğinde önemli artıș tespit etmiș olup, çalıșmamıza benzer șekilde bitki beslemede olumlu sonuçlar almıșlardır.

$\mathrm{K} \% 0.47$ (20 g kg-1 atık + 0 doz Hoagland) - \%2.6I (5 g $\mathrm{kg}^{-1}$ atık + \% 100 doz Hoagland), Ca ise \%2.35 (kontrol) \%3.07 (5 g kg-1 atık + \%100 doz Hoagland) arasında değișim göstermiștir (Șekil 3 ve Șekil 4). Smith (1966)'in $\mathrm{K}$ ve $\mathrm{Ca}$ için önerdiği referans değerleri (sırasıyla \% I.2 ve \%3.0) çalıșmamızdaki değerler ile uyum içindedir.

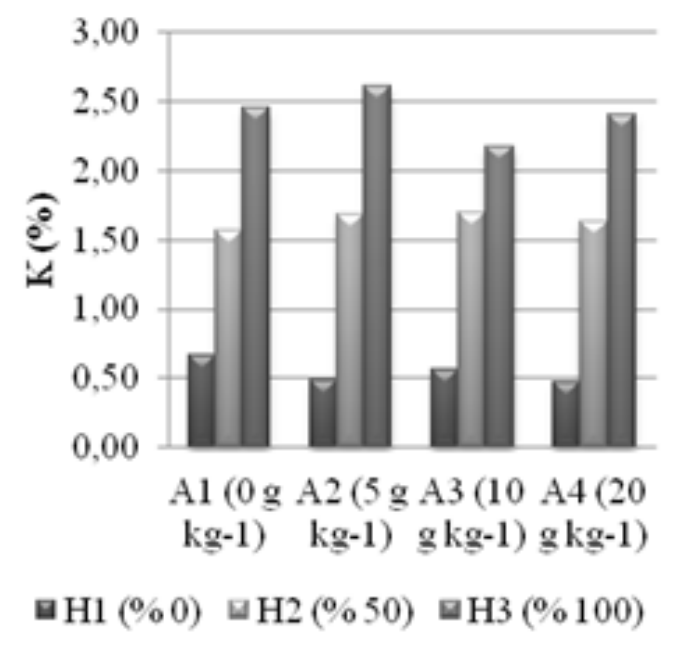

Șekil 3. Atık ve Hoagland uygulamalarının K (\%) kapsamı üzerine etkisi (A: Atık H: Hoagland) 


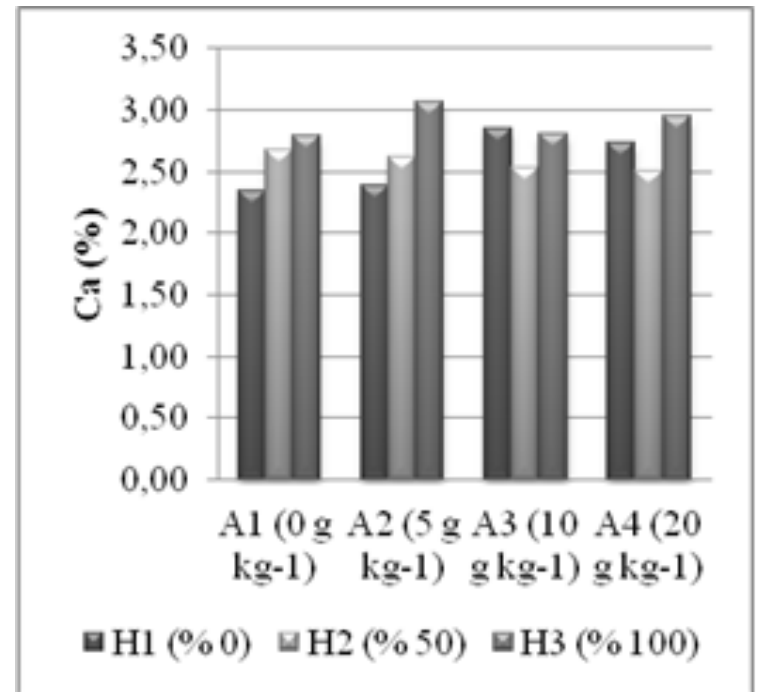

Sekil 4. Atık ve Hoagland uygulamalarını $\mathrm{Ca}$ (\%) kapsamı üzerine etkisi (A: Atık H: Hoagland)

$\mathrm{Mg} \% 0.28$ (20 g kg-1 atık + \%50 doz Hoagland) - \%0.34 (5 $\mathrm{g} \mathrm{kg}^{-1}$ atık +0 doz Hoagland), $\mathrm{Na}$ ise $158 \mathrm{mg} \mathrm{kg}^{-1}(20 \mathrm{~g} \mathrm{~kg}$ 1 atık + \%50 doz Hoagland) - $664 \mathrm{mg} \mathrm{kg-1}\left(0 \mathrm{~g} \mathrm{~kg}^{-1}\right.$ atık + 0 doz Hoagland) arasında değișim göstermiștir (Șekil 5 ve Șekil 6). Smith (1966), Sola ve ark. (2015) ve Jones ve ark. (199I)'nın önerdikleri referans değeri (\%0.30) araștırmadaki ile benzer bulunmuștur. Ayrıca, Na elementi kapsamında artıș yerine azalıș meydana gelmiștir. Bu yöndeki sonuç, uygulamaların $\mathrm{Na}$ kaynaklı tuzluluk gibi olumsuz bir etkiye yol açmadığını ortaya koymaktadir.

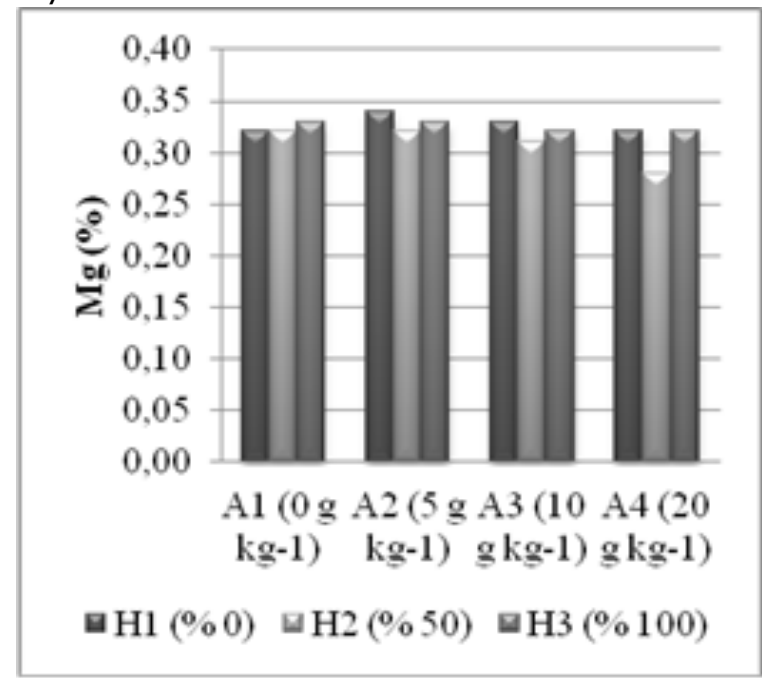

Sekil 5. Atık ve Hoagland uygulamalarının $\mathrm{Mg}$ (\%) kapsamı üzerine etkisi (A: Atık H: Hoagland)

Adiloğlu ve ark. (2016)' nın çalıșmasında; $\mathrm{P}, \mathrm{K}, \mathrm{Ca}$ ve $\mathrm{Mg}$ içeriklerindeki değișimler artan atık dozları ile önemli bulunmuș, akuakültür atığııın salata yetiștiriciliğinde kullanılabilecek alternatif bir organik gübre kaynağı

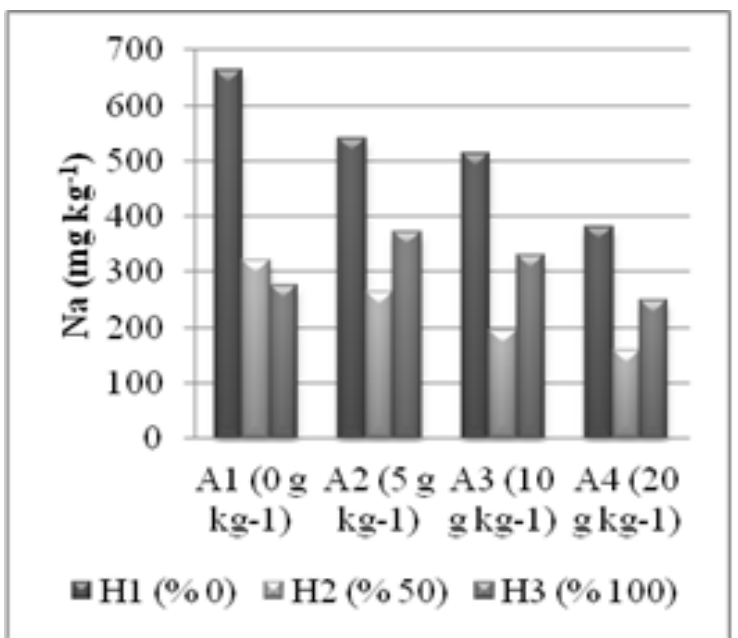

Șekil 6. Atık ve Hoagland uygulamalarının $\mathrm{Na}\left(\mathrm{mg} \mathrm{kg}^{-1}\right)$ kapsamı üzerine etkisi (A: Atık H: Hoagland)

olabileceği belirtilmiștir. Bu bulgular, araștırmadaki sonuçlar ile genel anlamda uyum içindedir.

Fe $73.3 \mathrm{mg} \mathrm{kg}^{-1}$ (10 g kg-1 atık + \%50 doz Hoagland) $126.7 \mathrm{mg} \mathrm{kg}^{-1}$ (20 g kg-1 atı +0 doz Hoagland), $\mathrm{Zn}$ ise $23.3 \mathrm{mg} \mathrm{kg}^{-1} \quad$ (kontrol) $-46.3 \mathrm{mg} \mathrm{kg}^{-1} \quad\left(20 \mathrm{~g} \mathrm{~kg}^{-1}\right.$ atı + $\% 100$ doz Hoagland) arasında değișim göstermiștir (Șekil 7 ve Șekil 8). Koo ve ark. (1984) ve Jones ve ark. (199I) tarafından turunçgillerde Fe (sırasıyla $35 \mathrm{mg} \mathrm{kg}^{-1}$ ve 60

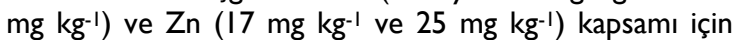
belirledikleri değerler, bu araștırmadaki değerlerden daha düșüktür. Özellikle toprak pH'sı yüksek alanlarda Fe klorozunun çok sık karșılașılan bir sorun olduğu düșünüldüğünde, $\mathrm{Fe}$ kapsamındaki bu artıș önemlidir. Ayrıca kullanılan atık materyal, Hoagland çözeltisine göre daha yüksek artıșa neden olmuștur.

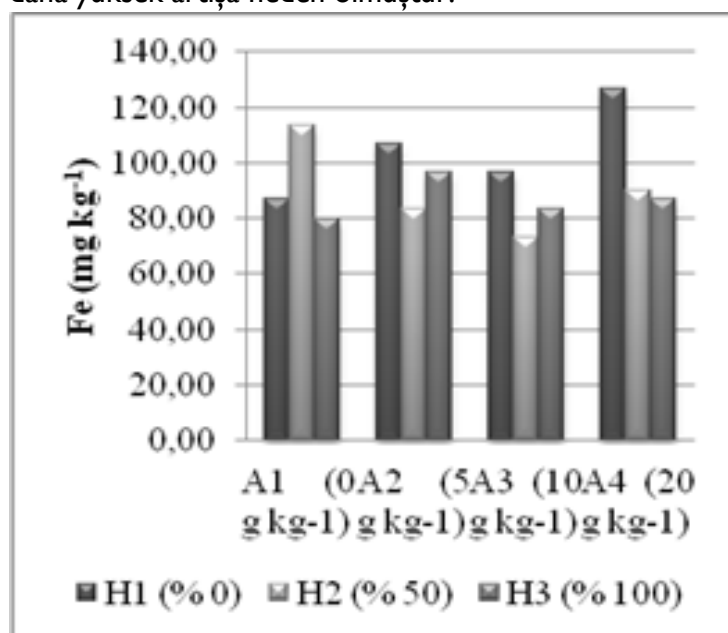

Șekil 7. Atık ve Hoagland uygulamalarının Fe $\left(\mathrm{mg} \mathrm{kg}^{-1}\right)$ kapsamı üzerine etkisi (A: Atık H: Hoagland)

$\mathrm{Zn}$ kapsamında ise, atık materyal, Hoagland etkisine benzer șekilde artıș yönünden etki yapmıștır. 


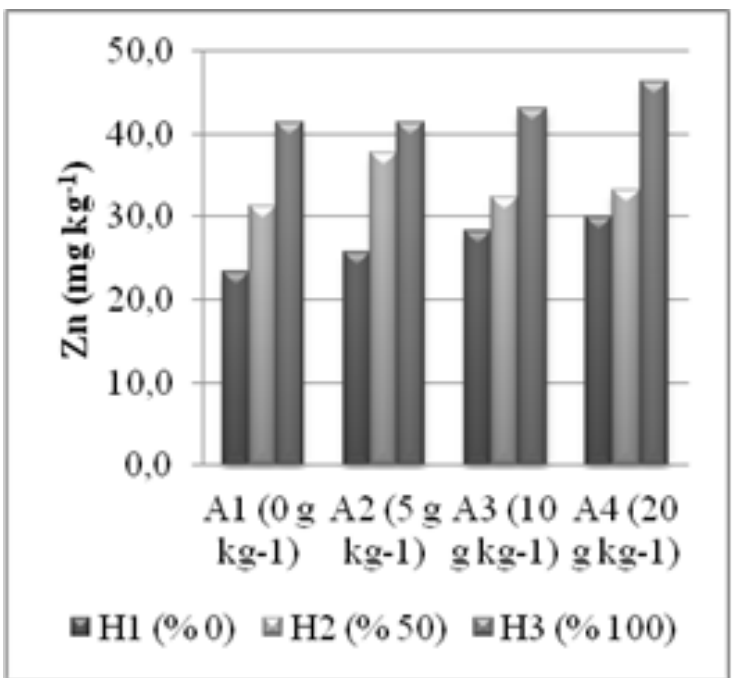

Șekil 8. Atık ve Hoagland uygulamalarının $\mathrm{Zn}\left(\mathrm{mg} \mathrm{kg}^{-1}\right)$ kapsamı üzerine etkisi (A: Atık H: Hoagland)

Mn $9.3 \mathrm{mg} \mathrm{kg}^{-1}$ (20 $\mathrm{g} \mathrm{kg}^{-1}$ atık +0 doz Hoagland)- 30.7 $\mathrm{mg} \mathrm{kg}^{-1}$ (20 g kg-1 atık $20 \mathrm{~g}+\% 100 \mathrm{doz}$ Hoagland) ve $\mathrm{Cu}$ ise $2.0 \mathrm{mg} \mathrm{kg}^{-1}\left(5 \mathrm{~g} \mathrm{~kg}^{-1}\right.$ atık+ \%50 doz Hoagland ve $5 \mathrm{~g}$ $\mathrm{kg}^{-1}$ atı $+\% 100$ doz Hoagland $)-19.7 \mathrm{mg} \mathrm{kg}^{-1}\left(10 \mathrm{~g} \mathrm{~kg}^{-1}\right.$ atık+ 0 doz Hoagland) arasında değișim göstermiștir (SSekil 9 ve Șekil 10). Koo ve ark. (1984) tarafından önerilen Mn kapsamı (17 mg kg-1) ile Yıldız ve ark. (2016)'nın tespit ettikleri Cu kapsamı değerleri (I0.5$\left.10.8 \mathrm{mg} \mathrm{kg}^{-1}\right)$ çalıșmamız ile uyumludur. Yapılan uygulamaların Mn kapsamını artırmadığı, buna karșın Hoagland uygulanmayan $5 \mathrm{~g} \mathrm{~kg}^{-1}$ ve $10 \mathrm{~g} \mathrm{~kg}^{-1}$ atık dozlarında Cu kapsamının arttığı görülmüștür.

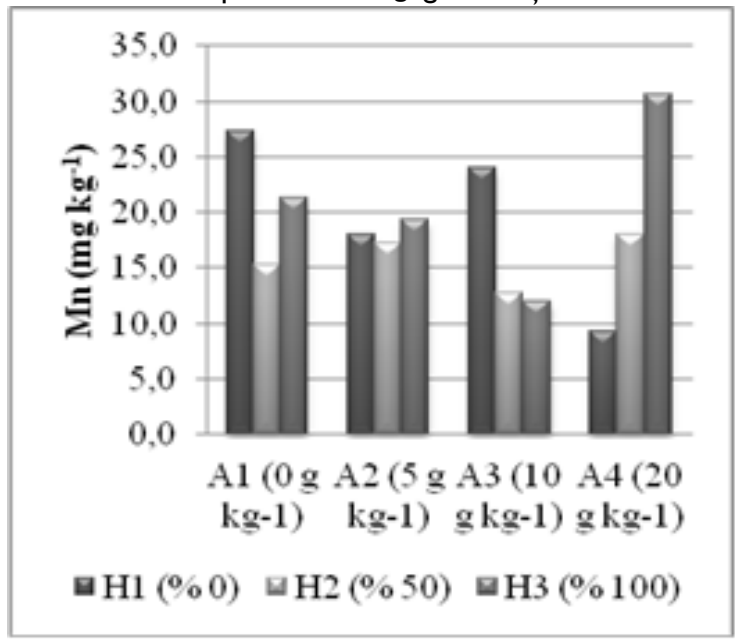

Șekil 9. Atık ve Hoagland uygulamalarının $M n\left(m g ~ g^{-1}\right)$ kapsamı üzerine etkisi (A: Atık H: Hoagland)

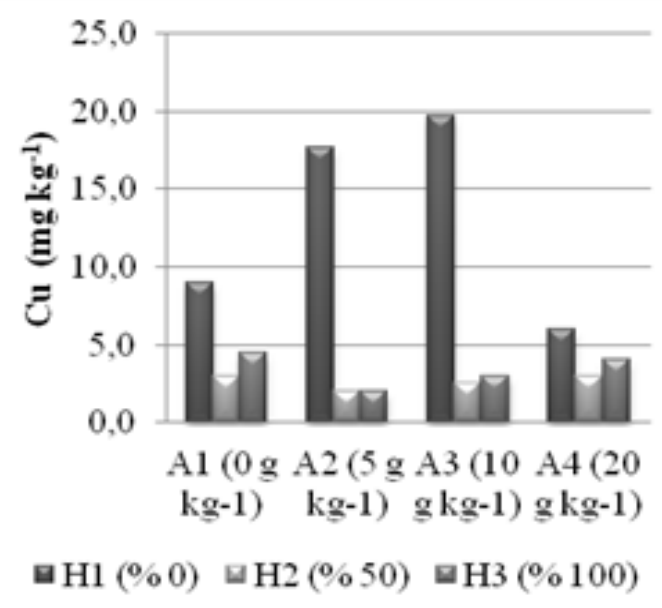

Șekil 10. Atık ve Hoagland uygulamalarının $\mathrm{Cu}\left(\mathrm{mg} \mathrm{kg}^{-1}\right)$ kapsamı üzerine etkisi (A: Atık H: Hoagland)

\section{SONUÇ}

Balık üretim çiftliklerinde ortaya çıkan havuz sedimantasyon atıklarının, özellikle tarımsal üretimde kullanılarak yeniden değerlendirilebilmesi, günümüzde çevrenin korunması ve sürdürülebilir üretim açısından son derece önemli bir konudur.

Çalıșmada elde edilen sonuçlara göre $\mathrm{N}, \mathrm{Zn}$ ve $\mathrm{Cu}$ artan atık dozuna bağlı olarak kontrole göre önemli düzeyde artmıș, önemli olmamakla birlikte $\mathrm{P}, \mathrm{Ca}$ ve Fe kapsamında da artıș olduğu tespit edilmiștir.

Artan Hoagland dozuna bağlı olarak genelde makro besin elementlerinde artıș meydana gelmiștir. Bu sonuç, beklenen bir durumdur. Ancak benzer șekilde atık dozlarının artıșına bağlı olarak yapraklarda da ilgili besin elementleri kapsamının genellikle artmıș olması, balık havuzu sedimantasyon atığının mineral gübre yerine ikame edilebileceğini göstermesi açısından önemli bir bulgu olarak değerlendirilmektedir. Bununla birlikte, bu konudaki çalıșmaların daha çok sayıda kültür bitkisinde yapılmasına ihtiyaç bulunmaktadır.

Atık çamurunda ağır metallerin bulunma olasılığı değerlendirildiğinde, atıkların tarımsal faaliyetlerde kullanılmadan önce ağır metal içeriklerinin de belirlenmesine ihtiyaç bulunduğu düșünülmektedir.

Havuz atığı sedimantasyon çamurunun tarımsal üretimde kullanılabilmesi; sadece bitki beslemeye değil aynı zamanda toprakların organik madde oranının artııılması ve alternatif ucuz girdi temini açısından da önemli katkı sağlayacaktır.

\section{TEȘEKKÜR}

Bu çalıșmaya katkılarından dolayı Muğla Sıtkı Koçman Üniversitesi Ortaca Meslek Yüksek Okulu Öğretim Üyesi Prof. Dr. Ibrahim Yokaș’a teșekkür ederim. KAYNAKLAR

Anonim (1989) SAS Institute Inc. SAS/STAT User's Guide: Version 6.0 Ed., SAS Institute Inc., Cary, North Carolina. 
Adiloğlu A, Açıkgöz FE, Adiloğlu S, Solmaz Y (2016) Artan Miktarlarda Akuakültür Atığı Uygulamasının Salata (Lactuca sativa L. var. crispa) Bitkisinin Bazı Makro ve Mikro Bitki Besin Elementi İçerikleri Üzerine Etkisi. Tekirdağ Ziraat Fakültesi Dergisi I3: 96-101.

Adler PR, Summerfelt ST, Glenn DM, Takeda F (2003) Mechanistic Approach to Phytoremediation of Water. Ecological Engineering 20: 25I-264.

Akat H, Demirkan ÇG, Yokaș i (20I3) Atık Su Arıtma Çamurlarının Süs Bitkisi Yetiștiriciliğinde Kullanımı. Uludağ Üniversitesi Ziraat Fakültesi Dergisi 27: 129141 .

Arienzo M, Christen EW, Quayle W, Kumar A (2009) A Review of the Fate of Potassium in the Soil-Plant System after Land Application of Wastewaters. Journal of Hazardous Materials 164:415-422.

Așık BB, Katkat AV, Aydınalp C, Bıyıklı M (2010) Arıtma Çamurlarının Tarımsal Özellikleri ve Ağır Metal İçerikleri. Ege Üniversitesi Ziraat Fakültesi Dergisi Özel Sayı 5. Bitki Besleme ve Gübre Kongresi Bildirileri, I5-I7 Eylül 2010, İzmir, 580-585.

Brod E., Haraldsen TK, Breland TA (2012) Fertilization Effects of Organic Waste Resources and Bottom Wood Ash: Result from a Pot Experiment. Agricultural and Food Science 21:332-347.

Celis J, Sandoval M, Barra R (2008) Plant Response to Salmon Wastes Sewage Sludge Used as Organic Fertilizer on Two Degraded Soils Under Greenhouse Conditions. Chilean Journal of Agricultural Research 68:274-283.

Celis J, Sandoval M (2010) Agricultural Potential of Salmon Wastes Used as Organic Fertilizer on Two Chilean Degraded Soils. 19th World Congress of Soil Science: Soil Solutions for a Changing World, I6 August 2010, Brisbane, 2256-2259.

Delibacak S, Ongun AR (2016) Influence of Treated Sewage Sludge Applications on Corn and Second Crop Wheat Yield and Some Properties of Sandy Clay Soil. Turkish Journal of Field Crops 21: 1-9, doi: 10.17557/tjfc.88475.

Demir K., Çakırer G (2014) Akuaponik Kültür. Tarım Gündem Dergisi 23: 32-34.

Demirkan GÇ, Akat H, Yağmur B (2017) Farklı Atık Materyallerin Matthiola incana 'Iron Rose' Yetiștiriciliğine Etkisi. Mediterranean Agricultural Sciences 30: 173-I78.

Eid AR, Hoballah EM, Mosa SEA (2014) Sustainable Manegement of Drainage Water of Fish Farms in Agriculture as a New Source for Irrigation and BioSource for Fertilizing. Agricultural Sciences 5: 730742.

Graber A, Junge R (2009) Aquaponic Systems: Nutrient Recycling from Fish Wastewater by Vegetable Production. Desalination 246: 147-156.

Illera-Vives M, Labandeira SS, Brito LM, Lopez-Fabal A, Lopez-Mosquera ME (20I5a) Evaluation of Compost from Seaweed and Fish Waste as a Fertilizer for Horticultural Use. Scientia Horticulturae 186: 101107.
Illera-Vives M, Lopez-Fabal A, Lopez-Mosquera ME, Ribeiro HM (20I5b) Mineralization Dynamics in Soil Fertilized with Seaweed-Fish Waste Compost. Journal of the Science Food and Agriculture 95: 3047-3054.

Jones Jr, Benton J, Wolf B, Mills HA (199I) Plant Analysis Handbook. I. Methods of Plant Analysis and Interpretation. Micro-Macro Publishing, Athens.

Kacar B (1972) Bitki ve Toprağın Kimyasal Analizleri II. Bitki Analizleri. Ankara Üniversitesi Ziraat Fakültesi Yayınları 453- Uygulama Kılavuzu I55, Ankara.

Koo RCJ, Anderson CA, Stewart I, Tucker DPH, Calvert DV, Wutscher HK (1984) Recommended Fertilizers and Nutritional Sprays for Citrus (Editor: R.C.J. Koo). Agricultural Experiment Stations Institute of Food and Agricultural Sciences. University of Florida, Florida.

Mills AH, Jones JB (1996) Plant Analysis Handbook II, A Pratical Sampling, Preparation, Analysis and Interpreparetion Guide, Micro Macro Publishing, Athens, Georgia.

Moccia R, Bevan D, Reid G (2007) Composition of Fecal Waste from Commercial Trout Farms in Ontario: Macro and Micro Nutrient Analyses and Recommendations for Recycling. Final Report Submitted to the: Ontario Sustainable Aquaculture Working Group Environment Canada. Aquaculture Centre University of Guelph.

Nair J, Seckiozoic T, Anda M (2006) Effect of preComposting on Vermicomposting of Kitchen Waste. Bioresource Technology 97: 2091-2095.

Naylor SJ, Moccia RD, Durant GM (1999) The Chemical Composition of Settleable Solid Fish Waste (Manure) from Commercial Rainbow Trout Farms in Ontario, Canada. North American Journal of Aquaculture 6l:21-26.

Palada MC, Cole WM, Crossman SMA (1999) Influence of Effluents from Intensive Aquaculture and Sludge on Growth and Yield of Bell Peppers. Journal of Sustainable Agriculture 14: 85-103.

Pereira BFF, He ZL, Stoffella PJ, Melfi AJ (20II) Reclaimed Wastewater: Effects on Citrus Nutrition. Agricultural Water Management 98:1828-I833.

Rakocy JE, Shultz RC, Bailey DS, Thoman ES (2004) Aquaponic Production of Tilapia and Basil: Comparing a Batch and Staggered Cropping System. Acta Horticulturae 648: 63-69.

Rebecca LJ, Anbuselvi S, Medok P, Sarkar D (2014) Effect of Marine Waste on Seed Germination. Journal of Chemical and Pharmaceutical Research 6:581-584.

Smith PF (1966) Leaf Analysis of Citrus, In: Childers, N.F. (Ed.), Fruit Nutrition Horticultural Publish, New Jersey, pp: 208-228.

Smith JH (1985) Fertilizing Agricultural Land with Rainbow Trout Manura for Growing Silage Corn. Soil Science Society of America Journal 49:I 3 I - I 34.

Sola LG, Sánchez FG, Pérez JGP, Gimeno V, Navarro JM, Moral R, Nicolás JJM, Nieves M (2015) Rapid Estimation of Nutritional Elements on Citrus Leaves by Near Infrared Reflectance Spectroscopy. 
Frontiers in Plant Science, 23 July 2015 https://doi.org//0.3389/fpls.2015.0057I. Erișim Tarihi: $01 / 05 / 2017$.

Tuna AL, Bürün B, Yokas I (20I2) Kireçle İșlem Görmüș Kentsel Atık Suların Toprağın $\mathrm{pH}$, EC ve Elementel Kapsamı ile Mısır Bitkisinin (Zea mays) Beslenme Durumu, Bazı Fizyolojik Özellikleri ve Verimi Üzerine Etkileri. Ekoloji 21: 66-73.doi: 10.5053/ekoloji.20I 2.848

Uzun P, Bilgili U (20II) Arıtma Çamurlarının Tarımda Kullanılma Olanakları. Uludağ Üniversitesi Ziraat Fakültesi Dergisi 25:|35-|46.
Wang X, Olsen LM, Reitan KI, Olsen Y (20I2) Discharge of Nutrient Wastes from Salmon Farms: Environmental Effects, and Potential for Integrated Multi-trophic aquaculture. Aquaculture Environment Interactions 2:267-283.

Yıldız E, Kaplankıran M, Uygur V (2016) Farklı Anaçlar Üzerine Așılı Fremont Mandarini Yapraklarındaki Bitki Besin Maddelerinin Mevsimsel Değișimleri. Mustafa Kemal Üniversitesi Ziraat Fakültesi Dergisi 21: $21-30$ 